\title{
Professor Elio Lugaresi's contributions to neurology and sleep disorders
}

\author{
As contribuições do Professor Elio Lugaresi para a neurologia e os distúrbios do sono \\ Fernando Tensini, Adriana Moro, Renato Puppi Munhoz, Tallulah Spina Silva, Hélio Afonso Ghizoni Teive
}

\begin{abstract}
The authors present a brief historical review of the most important contributions by Professor Elio Lugaresi, of the University of Bologna, Italy, to neurology and sleep disorders.
\end{abstract}

Key words: neurology, sleep medicine specialty, sleep disorders.

\section{RESUMO}

Os autores apresentam uma breve revisão histórica sobre as mais importantes contribuições do Professor Elio Lugaresi, da Universidade de Bolonha, Itália, para a Neurologia e para os distúrbios do sono.

Palavras-Chave: neurologia, medicina do sono, transtornos do sono.

Major progress has been made in the field of neurology throughout the world in recent years. In Europe, Italian neurology stands out particularly, and Italian neurologists currently have the second largest number of publications in indexed journals after their German counterparts ${ }^{1}$. Italian neurology researchers have made significant contributions through their studies in different areas, such as neuropsychology, movement disorders, multiple sclerosis, neurogenetics, sleep disorders and neuroimaging ${ }^{1}$. Professor Elio Lugaresi, of the University of Bologna, Italy, is one of the most renowned neurology researchers worldwide and was president of the Italian Neurology Society from 1984 to $1987^{1,2}$. Working mainly in the field of sleep disorders, he has been responsible for the original descriptions of various illnesses and has made significant contributions to many diseases ${ }^{2}$. The aim of this paper was to provide a brief review of professor Lugaresi's main contributions to neurology and sleep disorders.

\section{PROFESSOR ELIO LUGARESI}

Professor Elio Lugaresi graduated from medical school at the University of Bologna in 1952 and completed his residency in neurology at the same university between 1952 and

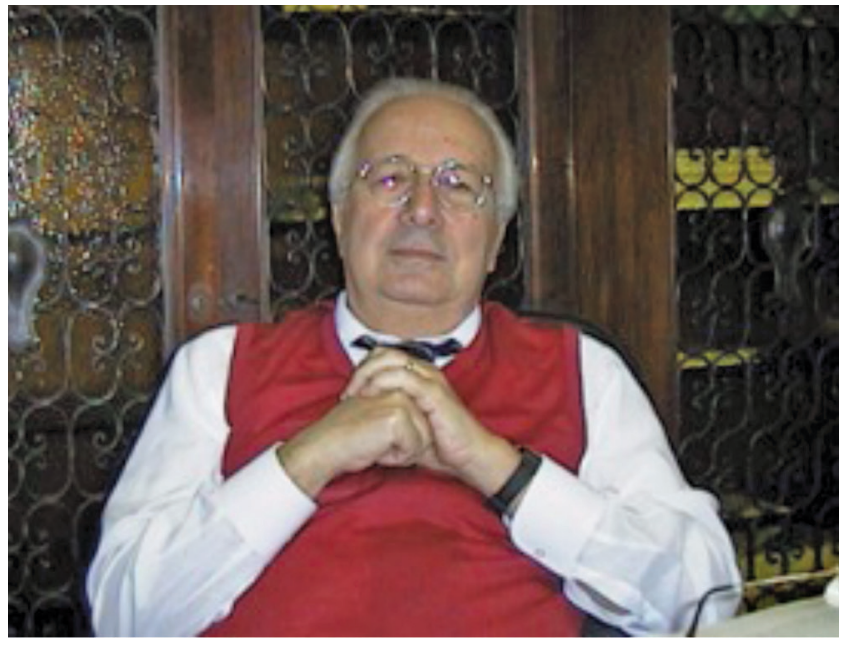

Professor Elio Lugaresi.

1958, having trained in electroencephalography in Marseille, France, between 1956 and 1957². Emeritus professor of neurology at the University of Bologna and founder and former editor of the Italian Journal of Clinical Neurophysiology, he is on the editorial board of a number of neurological journals and is a member (in many cases honorary) of countless medical and scientific societies ${ }^{2}$. Professor Lugaresi

Neurology Service, Hospital de Clínicas, Universidade Federal do Paraná (UFPR), Curitiba PR, Brazil.

Correspondence: Hélio Afonso Ghizoni Teive; Rua General Carneiro 1103 / 102; 80060-150 Curitiba PR - Brasil; E-mail: hagteive@mps.com.br

Conflict of interest: There is no conflict of interest to declare.

Received 21 January 2013; Received in final form 20 March 2013; Accepted 27 March 2013. 
has published various books and book chapters and has been awarded a range of national and international prizes, most notably by Ottorino Rossi award of "C. Mondino" Foundation from University of Pavia, the American Academy of Neurology (the Potamkin Prize among others), the International Federation of Clinical Neurophysiology (the Giuseppe Moruzzi award) and the Prix InterbrewBaillet Latour De La Sante ${ }^{2}$. To date, professor Lugaresi has published over 500 scientific articles, of which 400 appeared in indexed journals (PubMed). His main scientific contributions have been mainly in the field of epilepsy (a description of epilepsy with ecstatic seizures, the so-called Dostoevsky epilepsy, and epilepsies trigged by mental arithmetic, card games and draughts $)^{2}$. However, the contributions of this renowned Italian professor to the field of sleep disorders are far more numerous.

\section{PROFESSOR LUGARESI AND SLEEP DISORDERS}

Following is a summary of professor Lugaresi's main contributions to the field of sleep disorders.

\section{Propriospinal myoclonus}

Among the many types of myoclonus there is a subgroup of spinal origin consisting of segmental spinal myoclonus and propriospinal myoclonus (PSM). PSM is considered to originate in the spinal cord and spread up and down the propriospinal pathways. Axial myoclonus of propriospinal origin was described by Marsden et al. in 1991³. The Bologna school, headed by professor Lugaresi, studied propriospinal myoclonus as a cause of insomnia. When this kind of myoclonus occurs during relaxation (the relaxed wakefulness state prior to falling asleep referred to by Critchley as "predormitum") and drowsiness, it may cause severe insomnia ${ }^{4}$.

\section{Restless legs syndrome}

Restless legs syndrome (RLS), formerly known as "Ekbom's syndrome", is a sensorimotor disorder defined in 1945 by Karl-Axel Ekbom, who gave the first detailed clinical description of the disease $\mathrm{e}^{5,6}$. One important component of this condition that was not described by Ekbom is "nocturnal myoclonus", which later became known as "periodic limb movements in sleep" (PLMS). PLMS occurs in nearly $90 \%$ of patients with RLS ${ }^{7}$. Periodic limb movements are currently defined as limb movements that occur during sleep or wakefulness, with muscle activation in a sequence of at least four muscle contractions lasting $0.5-5.0$ seconds and recurring at intervals of 5-90 seconds in polysomnographic studies.

\section{Snoring and sleep apnea}

Lugaresi and his group have published several studies into snoring (since 1975) and obstructive sleep apneas (since 1980). They emphasized the clinical and physiopathological link between snoring and sleep apnea syndrome, as well as the relationship between the hemodynamic and ventilator effects of obstructive apneas, and were the first to implicate snoring and obstructive sleep apneas as risk factors for cardiovascular disease $\mathrm{e}^{8-10}$.

\section{Hypnogenic paroxysmal dystonia/nocturnal epileptic syndrome/nocturnal frontal lobe epilepsy}

In 1981, Lugaresi and Cirignotta ${ }^{11}$ described a peculiar condition known as hypnogenic paroxysmal dystonia for the first time in a paper with the title "Hypnogenic paroxysmal dystonia: epileptic seizure or a new syndrome?”. The authors described five patients with nocturnal episodes characterized by coarse, often violent movements of the limbs that occurred almost every night during NREM sleep and were not associated with EEG abnormalities ${ }^{11}$. Later, in 1986, Lugaresi, Cirignotta and Montagna ${ }^{12}$ published a case series of 12 patients with sleep-related seizures characterized by predominantly dystonic hyperkinetic movements resembling paroxysmal kinesigenic dystonias and defined as nocturnal paroxysmal dystonia. This entity was subsequently considered a form of frontal lobe epilepsy (nocturnal frontal lobe epilepsy - NFLE). However, distinguishing NFLE from parasomnias continues to pose challenges $^{13,14}$.

\section{Fatal familial insomnia}

Fatal Familial Insomnia (FFI) was described by Lugaresi and his group in $1986^{15}$. The disease is characterized by an inability to sleep, dysautonomia (autonomic hyperactivation) and motor disturbances (including myoclonus, ataxia and pyramidal signs) with thalamic atrophy ${ }^{15,16}$. FFI is now defined as a hereditary prion disease caused by a mutation at codon 178 in conjunction with the met129 polymorphism on the same allele of the prior-protein (PrP) gene (PRNP) $)^{16,17}$. There are two forms of fatal insomnia: FFI and sporadic fatal insomnia $(\mathrm{SFI})^{16}$.

\section{Agrypnia excitata}

Agrypnia excitata (AE) is a new syndrome described by Lugaresi and Provini ${ }^{18}$ in 2001 characterized by an inability to sleep associated with motor and autonomic overactivation. The condition is caused by a dysfunction in thalamolimbic circuits ${ }^{19}$ and is characterized by loss of slow-wave sleep, oneiric stupor and motor and sympathetic activation, features shared by FFI, Morvan's chorea and delirium tremens ${ }^{18,19}$.

\section{Endozepine stupor}

This rare condition was first described in 1992 as idiopathic recurring stupor due to the presence of endogenous ligands for the benzodiazepine recognition sites on 
gamma-aminobutyric acid A receptors in the nervous system $^{20}$. In 1998 Lugaresi and his group defined endozepine stupor as being recurring stupor linked to endozepine-4 accumulation $^{21}$. In 2005, Cortelli et al. ${ }^{22}$ discussed the role of endozepines in recurring stupor.

\section{Catathrenia (nocturnal groaning)}

In 1983, De Roeck and Van Hoof published a case report with a description of a peculiar condition involving sleeprelated expiratory groaning ${ }^{23}$. The condition was described as REM-sleep-related parasomnia by Pevernagie et al. in $2001^{24}$. In the same year, the Bologna group published a case series of four patients presenting with nocturnal groaning, a new type of parasomnia sometimes present during both NREM and REM sleep (the latter being most common) ${ }^{25}$. Lugaresi's group proposed the term catathrenia for this condition $^{26}$.

\section{Hypersomniac-hypoventilatory syndromes}

Lugaresi's group also made contributions to this group of disorders, which includes Pickwickian syndrome (obesity-hypoventilation-hypersomnia), primary alveolar hypoventilation or Ondine's curse and "slow sleep" narcolepsy ${ }^{27,28}$.

\section{PROFESSOR LUGARESI AND MOVEMENT DISORDERS}

The contribution made by Lugaresi's group in this area involves sleep disorders and could be considered under the heading "sleep and movement disorders" ${ }^{29}$. The main disorders studied by the group include startle syndromes, hyperekplexia, epileptic myoclonias, periodic limb movements during sleep or nocturnal myoclonus, propriospinal myoclonus, nocturnal paroxysmal dystonia and conditions related to agrypnia excitata associated with REM sleep behavior disorders ${ }^{29}$. The relationship between orthostatic tremor, described in 1984 by Heilman $^{30}$, and essential tremor was suggested in 1887 by Lugaresi's group ${ }^{31,32}$ and in 1988 by Papa and Gershanik ${ }^{33}$.

In conclusion, in the last 50 years the Bologna school, headed by professor Lugaresi, has made a very significant contribution to the study of neurology. In the area of sleep disorders, the group has described and carried out many high-quality studies of conditions such as myoclonus, restless legs syndrome, periodic limb movement disorders, snoring, sleep apnea, nocturnal frontal lobe epilepsy, fatal familial insomnia (both sporadic and autosomal dominant inherited) and agrypnia excitata.

\section{References}

1. Federico A. Italian neurology: past, present and future. Functional neurology 2011;26:73-76.

2. Lugaresi E. Curriculum Vitae. Available at: http://ebookbrowse.com/ cv-elio-lugaresi-pdf-d186019098

3. Brown P, Thompson PD, Rothwell JC, Day BL, Marsden CD. Axial myoclonus of propriospinal origin. Brain: a journal of neurology 1991;114 (Pt 1A):197-214.

4. Montagna P, Provini F, Plazzi G, Liguori R, Lugaresi E. Propriospinal myoclonus upon relaxation and drowsiness: a cause of severe insomnia. Movement disorders: official journal of the Movement Disorder Society 1997;12:66-72.

5. Ekbom KA. Restless legs: clinical study of hitherto overlooked disease in legs characterized by peculiar paresthesia (Anxietas tibiarum), pain and weakness and occurring in two main forms, asthenia crurum paraesthetica and asthenia crurum dolorosa. Acta Med Scand 1945;158:1-123.

6. Teive HA, Munhoz RP, Barbosa ER. Professor Karl-Axel Ekbom and restless legs syndrome. Parkinsonism \& related disorders 2009;15:254-257.

7. Provini F, Vetrugno R, Meletti S, et al. Motor pattern of periodic limb movements during sleep. Neurology 2001;57:300-304.

8. Lugaresi E. Snoring. Electroencephalography and clinical neurophysiology 1975;39:59-64.

9. Lugaresi E, Cirignotta F, Mondini S, Montagna P, Zucconi M. Sleeprelated respiratory disorders. Italian journal of neurological sciences 1985;6:389-399.

10. Lugaresi E, Vela-Bueno A. Sleep-related respiratory disorders. Seminars in neurology 1987;7:259-268.

11. Lugaresi E, Cirignotta F. Hypnogenic paroxysmal dystonia: epileptic seizure or a new syndrome? Sleep 1981;4:129-138.
12. Lugaresi E, Cirignotta F, Montagna P. Nocturnal paroxysmal dystonia. Journal of neurology, neurosurgery, and psychiatry 1986;49:375-380.

13. Provini F, Plazzi G, Lugaresi E. From nocturnal paroxysmal dystonia to nocturnal frontal lobe epilepsy. Clinical neurophysiology: official journal of the International Federation of Clinical Neurophysiology 2000;111 Suppl 2:S2-8.

14. Bisulli F, Vignatelli L, Provini F, Leta C, Lugaresi E, Tinuper P. Parasomnias and nocturnal frontal lobe epilepsy (NFLE): lights and shadows--controversial points in the differential diagnosis. Sleep medicine 2011;12 Suppl 2:S27-32.

15. Lugaresi E, Medori R, Montagna P, et al. Fatal familial insomnia and dysautonomia with selective degeneration of thalamic nuclei. The New England journal of medicine 1986;315: 997-1003.

16. Montagna P, Gambetti P, Cortelli P, Lugaresi E. Familial and sporadic fatal insomnia. Lancet neurology 2003;2:167-176.

17. Goldfarb LG, Petersen RB, Tabaton M, et al. Fatal familial insomnia and familial Creutzfeldt-Jakob disease: disease phenotype determined by a DNA polymorphism. Science 1992;258:806-808.

18. Lugaresi E, Provini F. Agrypnia excitata: clinical features and pathophysiological implications. Sleep medicine reviews 2001;5: 313-322.

19. Lugaresi E, Provini F, Cortelli P. Agrypnia excitata. Sleep medicine 2011;12 Suppl 2:S3-10.

20. Rothstein JD, Guidotti A, Tinuper P, et al. Endogenous benzodiazepine receptor ligands in idiopathic recurring stupor. Lancet 1992;340: 1002-1004.

21. Lugaresi E, Montagna P, Tinuper P, et al. Endozepine stupor. Recurring stupor linked to endozepine-4 accumulation. Brain: a journal of neurology 1998;121 Pt 1:127-133. 
22. Cortelli P, Avallone R, Baraldi M, et al. Endozepines in recurrent stupor. Sleep medicine reviews 2005;9:477-487.

23. De Roeck J, Van Hoof E. Sleep-related expiratory groaning: a case report. Sleep Res 1983;12:377.

24. Pevernagie DA, Boon PA, Mariman AN, Verhaeghen DB, Pauwels RA. Vocalization during episodes of prolonged expiration: a parasomnia related to REM sleep. Sleep medicine 2001;2:19-30.

25. Vetrugno R, Lugaresi E, Plazzi G, Provini F, D’Angelo R, Montagna P. Catathrenia (nocturnal groaning): an abnormal respiratory pattern during sleep. European journal of neurology : the official journal of the European Federation of Neurological Societies 2007;14:1236-1243.

26. Vetrugno R, Lugaresi E, Ferini-Strambi L, Montagna P. Catathrenia (nocturnal groaning): what is it? Sleep 2008;31:308-309.

27. Lugaresi E, Coccagna G, Ceroni GB. [The Pickwickian syndrome and primary alveolar hypoventilation syndrome]. Revue neurologique 1967;116:678-679.
28. Coccagna G, Mantovani M, Ceroni GB, Pazzaglia P, Petrella A, Lugares E. [Hypersomniac-hypoventilatory syndromes. Physiopathological and nosographic relationships between the Pickwick syndrome, primary alveolar hypoventilation and "slow sleep" narcolepsy]. Minerva medica 1970;61:1073-1084.

29. Lugaresi E, Provini F. Sleep and movement disorders. Neurol Sci 2005;26 Suppl 3:s173-175.

30. Heilman KM. Orthostatic tremor. Arch Neurol 1984;41:880-881.

31. Martinelli P, Gabellini AS, Gulli MR, Lugaresi E. Different clinical features of essential tremor: a 200-patient study. Acta Neurol Scand 1987;75:106-111.

32. Gabellini AS, Martinelli P, Gulli MR, Ambrosetto G, Ciucci G, Lugares E. Orthostatic tremor: essential and symptomatic cases. Acta Neurol Scand 1990;81:113-117.

33. Papa SM, Gershanik OS. Orthostatic tremor: an essential tremor variant? Mov Disord 1988;3:97-108. 